\title{
ROSSO MALPELO (1878), INFRAHÉROE Y FANTASMA: MITOLOGÍAS DE LA
}

MINA Y EL INFIERNO ${ }^{1}$

José Manuel Pedrosa

Universidad de Alcalá - GIECO

El negro Hades se enriquece entre suspiros y lamentos

(Sófocles, Edipo Rey)

\section{Resumen}

Análisis del cuento Rosso Malpelo ("Malpelo el Pelirrojo"), publicado por el escritor naturalista y verista italiano Giovanni Verga en 1878. El cuento describe la dura explotación infantil en las minas italianas del siglo XIX. El análisis conecta el perfil literario del protagonista del cuento con el de muchos héroes mitológicos que realizan el viaje al infierno, el descensus ad inferos.

\section{Palabras clave}

Rosso Malpelo, Giovanni Verga, mina, minería, naturalismo, verismo, héroe, épica, tragedia, descensus ad inferos.

\begin{abstract}
Analysis of the tale Rosso Malpelo ("Malpelo the Redhead"), published in 1878 by the Italian writer Giovanni Verga, exponent of the naturalist and verista movements. The story describes the harsh child labor in Italian mines during the nineteenth century. The analysis connects the literary profile of the protagonist of the story with many mythological heroes that go to hell (descensus ad inferos).
\end{abstract}

\section{Keywords}

Rosso Malpelo, Giovanni Verga, mine, mining, naturalism, verismo, hero, epics, tragedy, descensus ad inferos.

\section{Rosso Malpelo, ¿en la mina o en el infierno?}

Por la misma lógica por la que hay en nuestro imaginario superhéroes --y no me refiero solo a los del cómic y el cine de masas, sino a cualquier encarnación positiva,

1 Agradezco sus orientaciones y consejos a José Luis Garrosa y Óscar Abenójar.

2 Universidad de Alcalá. Correo: jmpedrosa2000@yahoo.es. Recibido: 11-08-2014. Aceptado: 27-112014 
elevada, sobrehumana del héroe-, tiene que haber también infrahéroes. Los superhéroes y los infrahéroes no son exactamente equiparables -aunque tengan mucho en comúncon los héroes épicos o vencedores -los primeros-, ni con los héroes trágicos o vencidos -los segundos-. Entre otras razones, porque el super-y el infra- antepuestos aportan matices de espacialidad que desbordan la simple dicotomía de vencedores y vencidos. Y más en esta ocasión en que me propongo reflexionar sobre el ser y el significado de los (infra-)trabajadores de las minas, que son infra- no solo por trágicos, por vencidos y porque se ven obligados a vivir físicamente en el inframundo; también porque no gozan de ninguna posición simbólicamente elevada con respecto a los demás, algo que sí caracteriza a los superhéroes: el lugar de los infrahéroes se halla por debajo de todos, en el escalafón físico y simbólico más hundido, oscuro y sin perspectivas de redención.

La acepción que voy a desarrollar en este artículo identifica al infrahéroe con un sujeto que vive instalado dentro de todas esas duras coordenadas. El niño minero Rosso Malpelo, cuyo funcionamiento como infrahéroe literario vamos a analizar, manifiesta rasgos opuestos a los del héroe convencional: es pobre, feo, débil, sucio, marginado, andrajoso, a veces generoso pero también en ocasiones cruel, se le considera gafe o asociado a la desgracia, aparte de compinchado con el diablo, y está siempre falto del amor y de la amistad de los demás -excepto del amor de su padre y de la amistad del mísero Renacuajo, quienes mueren antes que él-. Sufre, además, la muerte trágica y sin mayores trámites ni miramientos de los esclavos: lo contrario de lo que sucede con las aparatosas muertes y honras fúnebres de los (super)héroes. Que Rosso Malpelo -igual que otros infrahéroes- incumpla, incluso invierta o subvierta, todos los requisitos y marcas que cabe esperar que brillen en un héroe es, en cualquier caso, prueba de que la caracterización del infrahéroe depende -aunque sea en riguroso negativo- de la del (super)héroe.

Rosso Malpelo -Malpelo el pelirrojo- es el niño protagonista del cuento homónimo publicado en 1878 por el inmenso narrador italiano Giovanni Verga. Escrito en clave naturalista radical, verista según la corriente extrema del naturalismo que se desarrolló en Italia, meticulosamente inspirado en el criminal fenómeno de la explotación hasta la muerte de niños en las minas y canteras de la muy católica y apostólica Italia del siglo XIX, es uno de los cuentos más importantes, impactantes, emotivos y célebres de la literatura italiana y de la universal.

Rosso Malpelo nace, vive, trabaja y muere en las galerías de una cantera de piedra y arena, es decir, de una modalidad de mina. Tiene inscritas en su cuerpo y en su destino lo que pudiéramos considerar las "señales del destino heroico" 3 , aunque vueltas completamente del revés. Empezando por el color rojo de su pelo, que se tenía por repulsivo, y por su despectivo apodo consiguiente. Acusa todas las humillaciones

3 Tomo la expresión del título del libro de Gracia, 1991. 
y vejaciones posibles, y además las hace sufrir a quien es más débil aún que él. Y a su muerte, perdido sin que a nadie le apene su desaparición en las entrañas de la mina, asume la condición de fantasma del oscuro subsuelo, tan contraria a la del claro héroe épico: en vez de subir al podio de la fama, termina de precipitarse por el sumidero del horror.

Antes de centrarnos en la desgraciada biografía literaria del personaje de Verga, será útil hacer algunas reflexiones, de tipo más abstracto, sobre la lógica del relato en general -y del épico/trágico en particular- en relación con los espacios inframundanos. Porque la lógica del relato épico, y también la del relato trágico, prescribe una serie de itinerarios y de peripecias tópicos y previsibles. Y entre los logros que han de formar parte casi obligada del currículum del héroe está el del descensus ad inferos: es decir, la bajada a un espacio inferior, que puede ser el infierno o algún lugar muy parecido ${ }^{4}$ El de Rosso Malpelo será, como iremos apreciando, uno de los casos de descensus ad inferos más dramáticos y perturbadores de los que hay registro literario.

Conviene advertir, antes de nada, que el imaginario mítico de muchas culturas suele articular el espacio simbólico en tres niveles esenciales -el del superos, medio, inferos, que corresponden más o menos a cielo, tierra, infierno-, que se caracterizan por la estabilidad de sus instituciones y pobladores; entre esos tres espacios quedan otros dos -las franjas intersticiales del aire y el subsuelo- que se hallan caracterizados por su inestabilidad. Para entendernos: el cielo es el lugar de los dioses celestiales, los ángeles, los santos; la tierra, de los humanos; y el infierno, de los dioses y demonios de ultratumba, y de los muertos. En contraste, el aire es considerado el espacio de los inquietos espíritus del aire y de la tormenta, o de las brujas; y el subsuelo, de los demonios que se mezclan con los asuntos humanos, los enanos, duendes, dragones, y otros seres monstruosos, relacionados con la violencia, la oscuridad, el caos.

Conforme a una manera de imaginar muy arraigada en muchísimas culturas, los humanos habitan la tierra mientras están vivos, y pasan a quedar clasificados en el cielo o en el infierno -dependiendo de las obras que hayan hecho- después de muertos. Es creencia muy común que hay ánimas en pena que se quedan trágicamente atrapadas en los espacios intersticiales, con el ansia de morir de manera definitiva para poder quedar clara y confortablemente clasificadas. Solo los héroes están en condiciones de transitar épicamente por los espacios del aire o del subsuelo, pero de manera provisional, transitoria: ni Superman, ni Ulises, ni ningún otro héroe pueden aguantar demasiado tiempo en el aire o en el subsuelo, y mientras se encuentran en tales espacios sienten gran angustia y deseos de volver a quedar clasificados en el espacio que sienten como propio, que es el de la tierra ${ }^{5}$.

$4 \mathrm{Al}$ respecto véase Descensus (1995).

5 He reflexionado más en detalle sobre esta cuestión en mi artículo PEDROSA, en prensa. 
Dentro de estas coordenadas espaciales y simbólicas resulta más fácil entender el signo trágico de Rosso Malpelo: aunque parido - por una madre que le desprecia- en el suelo mísero de una choza de mineros, es obligado a trabajar en las entrañas de la mina desde una edad tempranísima hasta el final, y a pasar por tanto en el inframundo -en el que al final se adentrará para no volver- la mayor parte de su corta existencia. A su muerte no solo le quedarán los míseros títulos de infrahéroe y de vencido, sino también el de fantasma, que es el súmmum de lo bajo, de lo oscuro, de lo angustioso.

Pero, antes de seguir desgranando detalles de la biografía literaria de Rosso Malpelo, quedan algunas generalidades sobre las que reflexionar en relación con el inferos en el que se vio obligado a pasar su vida y a encontrarse con la muerte.

\section{EL DESCENSO AL INFIERNO Y EL DESCENSO AL PURGATORIO}

Desde que Gilgamesh visitase el mundo submarino para arrancar de él la planta de la inmortalidad, y Teseo el palacio de Creta para enfrentarse al Minotauro, o desde que Ulises y Eneas bajasen a los infiernos para conversar con los espectros de sus respectivos padres, hasta las expediciones de Harry Potter por las galerías subterráneas de Hogwarts, o de los aficionados a los videojuegos por sus tortuosos laberintos, la visita al infierno ha sido y es uno de los trámites más tópicos, esperados y reclamados por lectores y espectadores de cualquier época y lugar.

¿Qué héroe puede sustraerse a la fascinación de introducirse en alguno de los avatares infinitos en que se desdobla el infierno? Los versos atemorizados de Dante que daban cuenta del inferno por el que le guió Virgilio; el relato maravilloso de don Quijote tras subir de la cueva de Montesinos; el descenso de Van Helsing para eliminar en su mismo sepulcro a Drácula; el terror de Tom Sawyer en la cueva de la que al final saldría él, pero no su enemigo el indio Joe; los jadeos perversos de Orson Welles en su intento de escapar por las turbias alcantarillas de Viena en The Third Man (1949); los acentos alucinados de Borges cuando buscó describir el Aleph del sótano -bajando unas escaleras- de la casa de la calle Garay de Buenos Aires; la gesta de Gregory Peck, David Niven y Anthony Quinn al acceder a la cripta que hicieron saltar por los aires junto con The Guns of Navarone (1961), son variantes del descenso al otro mundo que han quedado fijadas de manera indeleble en la memoria cultural de la humanidad.

Hay, en cualquier caso, algo que distingue el modo de funcionar de la mina del modo de funcionar del infierno: una mina es un espacio de trabajo, de explotación económica de los sujetos de una clase dominada por parte de los sujetos de una clase dominante, de generación de materias primas que desde allí son inyectadas y transformadas en riqueza en un circuito económico exterior; mientras que un infierno es un espacio de penitencia y castigo, de explotación no económica de los sujetos dominados por parte de los dominantes -los dueños de ese infierno-; de no generación de bienes que hayan 
de pasar a algún circuito económico exterior o a ser contabilizados como riqueza útil.

El trabajo de la mina responde a una lógica económica brutal -sirve para algo, o para que se lucre alguien-, mientras que las penas del infierno responden a una falta de lógica económica no menos brutal -no sirven para nada, o no sirven para que se lucre nadie-. La labor de la mina es útil para que el trabajador haga un esfuerzo del que reciba réditos insuficientes, que apenas le llegan para sobrevivir en el presente; y para que el dueño de la mina obtenga, en paralelo, unos excedentes que podrá disfrutar en el futuro. En contraste, las penas del infierno no generan ningún beneficio presente ni futuro, pues son simples compensaciones de déficits que quedaron comprometidos en el pasado: por poner un ejemplo, el trabajo de Sísifo en el infierno, empujando una piedra por una pendiente, y volviéndola a subir cada vez que la piedra volvía al punto de partida, no servía para que Sísifo viviese mejor, ni para que ni siquiera viviese puesto que estaba ya muerto- ni contribuyese a su imposible redención, ni generaba ningún beneficio ni ninguna riqueza de la que pudiera servirse el amo del infierno ni nadie más.

El trabajo de la mina es inútil porque nunca termina de saldar -siguiendo el guion agotador de la repetición con vuelta a empezar, o del círculo vicioso- las cuentas pendientes del pasado. Es por ello que los niños esclavizados en Indiana Jones in the Temple of the Doom (1984) se hallan encerrados en una mina que se parece a un infierno, pero que no lo es exactamente, puesto que su trabajo allí resulta útil para sus captores, que extraen réditos económicos del mineral; si fueran esclavos de un infierno en sentido estricto, los amos de ese infierno los emplearían en cambiar las piedras simplemente de lugar, con lo que su trabajo sería perfectamente inútil y su esfuerzo no se traduciría en ningún valor. En fin: que la mina es el espacio inicial de un proceso económico, y el infierno es su simple fin, su llana cancelación.

Religiones como la católica y la copta han articulado un concepto, el del purgatorio, que alivia el callejón sin salida que es, en términos de lógica económica, el infierno. El purgatorio constituye un espacio y un tiempo de transición, en que los condenados sí pueden, mediante el cómputo de su arrepentimiento, de su sufrimiento, y de las inversiones simbólicas que desde el mundo hagan sus allegados -en forma de oraciones, misas, limosnas, etc.-, ir descontando penas y días de estancia en el inframundo, y albergar esperanzas de alcanzar algún día un saldo neutro que permita el ingreso en el cielo. El purgatorio ha sido y sigue siendo una estrategia muy eficaz para quitar relevancia a la idea de puro y negativo castigo -tan parecida a la idea de venganzaque encarna el infierno, y para sustituirla por una mucho más presentable y positiva ética en que la redención sea posible. La lógica del purgatorio y la posibilidad que ofrece de descontar y redimir penas y días tiene mucho que ver con la lógica de la reencarnación de muchas religiones orientales -con la expectativa de progreso en la vida siguiente, en el caso de que se obre bien en esta-, aunque hay entre ambas una 
diferencia importante: entre los creyentes respectivos, el purgatorio es un infierno efectivo -aunque transitorio- que se halla claramente estacionado en el inframundo, mientras que el espacio de la reencarnación de las almas en cuerpos de animales o personas es, en diversas religiones de Oriente, el espacio mismo del mundo.

El desdichado Rosso Malpelo vivió y murió, pues, en una mina en la acepción física, espacial y económica del término -pues alguien obtenía beneficios de su trabajo-; pero también en un infierno -ni siquiera en un purgatorio- en el sentido ético y simbólico, pues le fue siempre negada cualquier luz al final del túnel, cualquier posibilidad de redención.

\section{LA MINA, LA HERRERÍA, LA FÁBRICA}

La mina es, como ya he señalado, el cuasi infierno -pero no el infierno del tododel que los mineros extraen el mineral que a ellos les permite subsistir precariamente y a los dueños de la mina hacerse ricos. Un espacio adlátere a la mina puede ser la herrería. Y, en un sistema de producción más complejo o tecnologizado, puede ser también la fábrica. Si de la mina se extrae el mineral, en la herrería sufre una primera transformación y manipulación, y en la fábrica puede sufrir una transformación cuantitativa y cualitativamente superior.

Las condiciones de trabajo de la herrería son, para el trabajador, no mucho mejores que las de la mina: de esfuerzo doloroso, sudor, polvo, suciedad, trabajo infravalorado e infrapagado. Las condiciones de trabajo dentro de una fábrica fueron, en el Occidente del pasado, y todavía en muchos países de hoy, igualmente indignas, de práctica esclavitud. En el mundo occidental, las condiciones de trabajo en las fábricas han mejorado y se han humanizado -en general- en las últimas décadas, por más que el trabajo de la mano de obra siga estando infravalorado e infrapagado.

También son análogas, pero por el lado positivo, sobrevalorado y sobrepagado pues siempre se apropian de los excedentes-, las condiciones económicas de que gozan los dueños de la mina, de la herrería y de la fábrica. En el plano de cómo funciona su engranaje simbólico y mitológico, también hay analogías. Porque los dueños, aparte de disfrutar de los excedentes, solían y suelen disfrutar, en muchas tradiciones literarias y culturales, de atributos místicos, mágicos o carismáticos que sirven para reforzar su preeminencia y les ayudan a mantener el control sobre los trabajadores dominados. Ese estatus de superioridad carismática se asemeja en algunos extremos al estatus que se halla implantado en el infierno, cuyos dueños ejercen también una violencia religiosa, mágica o simbólica sobre los condenados.

Unos cuantos ejemplos sacados de épocas, tradiciones y registros bien diferentes, entre muchos que podríamos aducir, nos permitirán apreciar unos cuantos avatares 
de tales minas, herrerías o fábricas regidas por señores cuyo despotismo se reclama apoyado sobre bases mágico-místicas.

Piénsese en Hefestos, el dios griego de la herrería, quien ejercía su autoridad no solo de clase, sino también de carisma religioso, sobre los ayudantes que tenía en su fragua: el aprendiz Cedalión, los gemelos Cabiros y los gemelos Palicos, los Cíclopes y las Kourai Khryseai automáticas. Piénsese también en Reginn, el herrero infernal de la mitología germánica que tenía esclavizado -hasta que él se emancipó- al joven héroe Sigurd o Sigfrido, o en su avatar Alberich, otro oscuro herrero que dominaba también cruelmente a sus enanos en Das Rheingold (1869) de Wagner. Y miremos a la figura de Willy Wonka, el dueño de la fábrica de Charlie and the Chocolate Factory, novela (1964) de Roald Dahl y película (2005) de Tim Burton: reelaboración luminosamente amable y edulcoradamente capitalista del mito de la mina -convertida aquí en mina de chocolate-, de la herrería -trasmutada en pastelería- y de la fábrica -transfigurada en paraíso que hace felices a los simpáticos enanos que trabajan en ella-.

La esencia de todos estos relatos y personajes bebe, sin duda, de mitos y de tradiciones orales antiquísimos. Aunque no podamos detenernos ahora en los detalles, no será ocioso señalar que abundan todavía, en no pocos lugares de Hispanoamérica, las leyendas acerca del diablo que habita dentro de las minas, y a quien los trabajadores han de entregar ofrendas para que les permita salir con vida de ellas; o relatos acerca de las artes mágicas -perros guardianes prodigiosos, demonios serviles, hasta imágenes de santos que velaban para que no se escapasen ni se rebelasen los esclavos- que poseían los dueños de las minas y de los ingenios de azúcar o de tabaco, para tener física y mágicamente sometidos a sus trabajadores.

Este tipo de mitos, leyendas y cuentos acerca de señores místicos o carismáticos de las minas, herrerías o fábricas, se halla en conexión lateral con otro complejo mitológico que vamos a dejar simplemente apuntado aquí, dado que no tiene que ver con los espacios inferiores y cerrados, sino con los espacios medios y al aire libre: se trata de los mitos acerca de construcciones levantadas por trabajadores esclavizados por un señor que ejerce su autoridad mágica sobre ellos. Su recorrido es muy largo, y va desde la construcción mitológica de las murallas de Troya, que, por imposición de Zeus -a quien habían ofendido-, acometieron Poseidón y Apolo bajo la autoridad perversa de Laomedonte, el rey de Troya; hasta la novela Die schwarze Spinne (La araña negra, 1842) del suizo Jeremias Gotthelf, basada en una apretada amalgama de leyendas populares, que relata las desventuras que sufren los campesinos de un valle suizo, obligados por su tiránico señor, Hans von Stoffeln, a construir un castillo para él, y luego a plantar cien hayas en el plazo de un mes.

\section{MARCA CORPORAL, APODO, EXCLUSIÓN, BESTIALIDAD, FAMA: LAS SEÑALES -AL REVÉS- DEL HÉROE}


A Malpelo lo llamaban así porque era pelirrojo, y si era pelirrojo es porque se trataba de un chico malintencionado y ruin que prometía convertirse en un buen bribón. Como en la cantera todos lo conocían por Malpelo, incluso su madre había acabado olvidando su nombre de pila. Por lo demás, ella lo veía solamente el sábado por la noche, cuando pasaba por casa con lo poco que ganaba durante la semana y, como malpelo que era, era legítimo temer que se quedara con algunas monedas del jornal. Ante la duda, y para no equivocarse, la hermana mayor solía recibirlo a bofetones ${ }^{6}$.

En este párrafo inicial del cuento de Giovanni Verga se hallan cifradas algunas de las claves esenciales de la construcción poética e ideológica del personaje literario de Rosso Malpelo, Malpelo el Pelirrojo. La correlación entre su fisonomía -dominada por el color rojo del pelo-, el apodo que le roba el nombre y el trato ofensivo y la violencia que sufre desde que nace anudan un destino que no podrá derivar -dentro del marco del relato naturalista- sino hacia la tragedia. Unas líneas algo posteriores corroboran que Rosso Malpelo era tenido por

un pilluelo que nadie habría querido a su lado y que todos esquivaban como si fuera un perro roñoso, y lo acariciaban con la punta del pie cuando se les ponía a tiro.

Era en verdad un hocico feo, torvo, gruñón y salvaje (51).

Peor aún:

mientras el resto de obreros se comían su menestra formando un corro, y se distraían un poco, él se iba a un rincón con el cesto entre las piernas y allí roía el pan de ocho días, como hacen sus iguales, las bestias; y cada uno le decía algo insultándolo o tirándole una piedra, hasta que el jefe lo mandaba de vuelta al trabajo con un puntapié. Él engordaba entre golpes y se dejaba cargar aún más que el asno gris, sin soltar un lamento. Estaba siempre andrajoso y sucio de arena roja, pues su hermana, que se acababa de prometer, tenía otras cosas en la cabeza; no vestirlo. Tan conocido era en todo Monserrato y la Carvana que la cantera donde trabajaba la conocían por "la cantera de Malpelo", lo que molestaba, y mucho, al patrón (51).

En resumen, nuestro desdichado niño minero nace y vive bajo la marca adversa de su pelo rojo, tenido por signo de maldad y degeneración; recibe por ello un nombre falso y despectivo; es excluido de las relaciones sociales -y además agredido de manera permanente- por su familia y por sus compañeros; y obligado a vivir entre el polvo y la basura y a comer como lo haría un animal; hasta el extremo de que su desdicha se hace tan llamativa que el lugar en que malvive pasa a ser conocido como "la cantera de Malpelo".

Marcas todas y cada una de ellas, aunque vueltas completamente del revés, de las que caracterizan a tantos héroes: la señal inscrita sobre el cuerpo, el apodo alusivo a la fisonomía, la exclusión y exposición al margen de la comunidad, la fase de vida salvaje, con alimentos crudos o podridos y proximidad a lo bestial; $y$, al final, la fama

6 Sigo, en todas las citas, la estupenda versión en español publicada en VERGA (2009) 51. 
que se asocia al lugar de procedencia.

Serían precisas las páginas de una gruesa enciclopedia para ir desgranando el catálogo de los héroes que podrían funcionar como el positivo del largo currículum heroico que Rosso Malpelo encarna por la parte negativa. Habremos de conformarnos con glosas muy rápidas y breves, que alcancen simplemente para revelar al personaje tan cuidadosamente diseñado por Verga como el reverso exacto de una tradición de personajes míticos de arraigo inmemorial y universal.

Recuérdese, para empezar, que muchos héroes se hallan caracterizados por marcas corporales y fisonómicas muy definitorias de su carácter y de su destino: la herida en el talón de Aquiles, o las cicatrices en el muslo de Ulises, en la barbilla de Indiana Jones o en la frente de Harry Potter, o los estigmas de Cristo o de San Francisco, o la marca blanca en la espalda de Sigfrido, son ejemplos ilustres de señales inscritas sobre el cuerpo que condicionan o definen el estatus y el destino de tantos personajes carismáticos.

En el caso de Rosso Malpelo, es el color del cabello el que carga con el mayor -o peor- peso simbólico. El desdichado niño minero tiene la desgracia de ser pelirrojo, como, según las leyendas populares cristianas, era el traidor por excelencia, Judas 7. Rosso Malpelo nace, pues, bajo el estigma del mal que las tradiciones cristianas atribuían, por contaminación con la figura de Judas, a los pelirrojos. Podríamos ir más allá y decir que su pelo, con la carga simbólica negativa que se le asociaba y la función condicionante de su mal hado, se parece más al de Absalón, el hijo del rey David que sufrió el negro destino de morir cuando su larga cabellera -que le llevó a la perdiciónse enredó en las ramas de una encina (II Samuel 9-15), que al pelo lustroso y carismático de Sansón, cuya cabellera concentraba las señales más positivas del carisma heroico. Tampoco está adornada precisamente, la cabellera tenida por vergonzante de Rosso Malpelo, del carisma positivo de la "barba florida" que ennoblecía al Carlomagno de la Chanson de Roland, ni de la "barba conplida" o "vellida" o "luenga" que realzaba el perfil heroico del protagonista del Cantar de mio Cid. No hay pruebas que permitan vincular por vía directa, en fin, la figura del niño desdichado Rosso Malpelo con la niña acosada Caperucita Roja -que en la precursora versión del cuento de Perrault acababa irrevocablemente sus días en las tripas del lobo-, aunque los signos y colores, no muy diferentes, que marcan sus respectivas cabezas sirven al menos para corroborar, por dos vías diferentes, la potencia simbólica que pueden asumir las señales del cuerpo -y de la indumentaria- en el tejido semántico de las tramas literarias.

El apodo de Rosso Malpelo -motivado por su pelo- que recibe el niño minero, y que le roba su nombre y su identidad verdaderos, es, en definitiva, marca tópica -aunque malintencionadamente invertida, en su caso- de tantos héroes, desde Edipo -cuyo

7 Al respecto véase GUTIÉRREZ CARBAJO 1993. 
nombre significa "el de pies hinchados"-, Carlomagno, Sancho Panza o Palmerín de Oliva -quien fue encontrado a poco de nacer entre "muchas palmas e olivas" -, hasta la Cenicienta -o la propia Caperucita Roja-, Peter Pan -su nombre y el instrumento musical que toca remiten al dios mitológico Pan- o su enemigo el capitán James Hook -el "Garfio" -, Batman, Spiderman o nuestros traviesos Zipi y Zape.

Por cierto, que interesa adelantar aquí que el hecho de que la cantera en que vivió y murió Rosso Malpelo fuese muy conocida, "lo que molestaba, y mucho, al patrón" como "la cantera de Malpelo", tiene bastante que ver también con otra regla muy común de la gramática de lo heroico, y con el hecho -por desgranar unos pocos paralelos-, de que el topónimo de Saba haya pasado a la memoria eterna de la humanidad -aunque no se sabe siquiera dónde estaba el lugar- como la patria de la reina sabia que visitó a Salomón; de que los pueblos de Nazaret y de Asís -que de otro modo no conocería casi nadie- hayan quedado, ante todo, como los lugares de nacimiento de Jesús y de San Francisco; o de que La Mancha árida y humilde sea universalmente conocida como la región natal de don Quijote. Es muy sintomático -desde la lógica inversa que articula todo el relato de Verga- que el patrón no encontrase nada deseable la identificación de su mina con la triste figura de Rosso Malpelo, al contrario de lo que sucede en tantos lugares que buscan notoriedad a la luz de los grandes hombres que en ellos nacieron o vivieron.

El abandono por parte de la familia, la exclusión y exposición al margen de la comunidad, la vida salvaje que se ve obligado a llevar, entre desechos e inmundicias, alimentos escasos y viles, crudos o pasados, y bestias como el asno, son otros de los trámites que Rosso Malpelo cumple para quedar configurado como prototipo del infrahéroe inexorablemente trágico, humillado, quebrado. Todas esas desgracias y carencias suelen pesar sobre los (super)héroes, en efecto, en la muy localizada fase de su iniciación; pero son después, por lo general, feliz y absolutamente superadas, incluso invertidas, puesto que el relato épico suele terminar con la satisfacción hiperbólica de todas ellas. Ninguna compensación ni satisfacción alcanza, por el contrario, al niño minero del cuento de Verga, que se verá obligado a vivir en tan extremas condiciones desde el primero hasta el último día de su vida.

Será útil señalar aquí que los héroes abandonados, excluidos, expuestos en su infancia, han quedado muy bien registrados en nuestra memoria mitológica, desde Moisés o Edipo hasta Amadís de Gaula, Superman o Harry Potter. Los héroes obligados transitoriamente a comer alimentos crudos y a frecuentar la compañía de salvajes o de animales, son igualmente multitud, desde el Enkidu semisalvaje que se hizo compañero de Gilgamesh; los medievales Yvain y Merlín, que se transformaron en locos o en pájaros silvestres y se dedicaron a comer alimentos crudos en el bosque antes de volver a quedar agregados a la civilización; hasta el Robinson de Defoe, el Mowgli de Kipling o el Tarzán de Burroughs, que pasaron por fases de vida marcadas por lo 
salvaje, por la alimentación más elemental y por la proximidad a lo animal. Por su parte, los héroes que nacen y viven entre materias viles son también de lo más común, desde el Edipo recogido y criado entre pastores, ganados y establos; el Sigfrido que se crió entre el carbón de una herrería; el Cid al que algunas leyendas hacían hijo de molinero; el gigantesco Renuard, compañero del héroe francés Guillermo, que prefiere dormir en el hollín de la cocina antes que en una cama; Edmond Dantès, el Conde de Montecristo, encerrado durante muchos años en la más inmunda de las mazmorras; o el Oliver Twist que intentaba sobrevivir en el laberinto de Londres cubierto de suciedad. O la mismísima Cenicienta, por supuesto.

De modo que el pobre Rosso Malpelo, abandonado por todos, obligado a comer poco y mal, y más cerca de las bestias que de las personas, tenía, sin saberlo él, parientes lejanos en el olimpo de los héroes sometidos a parecidas penas de exclusión y de carencia, incluso de esclavitud. Por más que de tales héroes le diferenciase la condena de por vida que Rosso sufrió, frente a la provisionalidad de la exclusión de los demás.

No puedo resistir a la tentación de traer aquí a colación a un héroe escasamente conocido en Occidente, pero que puede ser una figura extraordinariamente reveladora dentro del cuadro comparativo que intento esbozar: Baybars I, quien desde la posición de esclavo cumano llegó a convertirse en sultán mameluco de Egipto y Siria en el siglo XIII, y al que abundantes leyendas épicas árabes, que han perdurado hasta hoy, describen como un niño esclavizado y maltratado, débil, enfermo y sucio, con el pelo extrañamente rubio y con uno o varios lunares o marcas de viruela -señales a un tiempo de su debilidad originaria y luego de su carisma heroico- en la cara. Una profecía había anunciado al virrey de Alepo que debía buscar y comprar un niño que tuviera tales rasgos al dueño de un mísero hamán -un baño oscuro, avatar de otro inframundo cuasi infernal- en el que se hallaría encerrado como esclavo, porque el destino dictaba que, con el tiempo, la criatura aquella llegaría a ser el monarca de todos:

Una de las predicciones decía que vendría de Basora un mameluco, originario del país de Persia, que un khawaja compraría en un haman, que estaría enfermo, que pasaría por Alepo acompañado de un grupo de mamelucos, que tendría en la frente siete marcas de viruela y que su llegada vendría acompañada de signos y presagios (La infancia: 86).

Pues bien: según una novela popular árabe que ensalzaba -en paralelo a otros relatos y textos que también lo hicieron- la vida de Baybars, El-Muzaffar, el virrey de Alepo, supo un día de la existencia de aquel niño del hamán, se acercó a él para que le mostrara su frente, lo reconoció por sus marcas de viruela, lo sacó de allí y empezó a preparar al joven para el destino carismático que le esperaba. Lo más significativo para nosotros puede que sea -por las analogías que muestra con la biografía literaria de Rosso Malpelo- el relato de las condiciones en que vivía el joven en el hamán, rodeado de suciedad y de sus propios excrementos hediondos, y víctima de todo tipo de humillaciones y malos tratos: 
$\mathrm{Al}$ entrar Qalaoun, fue asaltado por un olor nauseabundo. Al volverse, vio en un hueco a un joven flaco envuelto en una sábana de fieltro, aquejado de dolor de barriga y cuyo aspecto era muy pálido.

-¿Quién eres, chico?- le preguntó.

-Soy extranjero y estoy enfermo.

- ¿No te han dicho que el hamán es hoy para los mamelucos del rey? ¿Por qué te quedas para apestarnos? Puaf, bala versen - y le escupió a la cara.

El joven exclamó:

-Me escupes a la cara, ¿no temes a Dios, el Altísimo? Él nos ha creado a uno y a otro y siempre el mal vuelve a su autor. Dios te devolverá el mal que tú me haces, pues muy pronto, si Dios quiere, escupirás tu sangre.

Al escuchar a este moribundo dirigir tales palabras de maldición, se enfureció; empuñó uno de sus chanclos y se preparó para darle una paliza, cuando Edamor apareció de repente, frenó el brazo de Qalaoun y le impidió golpear; después le preguntó lo que pasaba. Qalaoun le dijo:

-Observa a este pequeño moribundo, ¡nos apesta!

-Que Dios le cure y cure a todos los musulmanes enfermos -replicó Edamor- pues en su aspecto, se ve bien que es extranjero (La infancia, 73).

El cotejo de los destinos de Baybars y de Rosso Malpelo no puede ser más revelador de lo dicotómicos que son el género del relato épico, por un lado, y de la novela naturalista, por el otro. Esclavizados los dos en agujeros -el hamán, la mina- muy parecidos al infierno, marcados por señales que en principio son deshonrosas para los dos -huellas de viruela, pelo como el de Judas-, golpeados, sucios, desnutridos, enfermos, indefensos, solos, Baybars acabará elevado al olimpo de los grandes héroes, en tanto que Rosso Malpelo no dejará de hundirse, sin remisión, en el más espectral de los abismos.

El naturalismo asumido como credo absoluto por Verga se nos muestra, de ese modo, bastante más crudo y radical que el realismo más amable y contemporizador que dominaba la literatura de su mismo siglo. Si ponemos, por ejemplo, a Rosso Malpelo frente a Oliver Twist, el inolvidable protagonista de la novela (1837-1839) de Charles Dickens, volveremos a apreciar que sus itinerarios vitales siguieron derroteros muy parecidos -Twist estaba esclavizado en la cueva de ladrones de Fagin, igual que Malpelo en la mina- hasta que el desdichado muchacho inglés quedó redimido y fue reintegrado a la alta sociedad inglesa de la que había sido arrebatado. El niño minero italiano, lejos de encontrar manos que le redimieran, no encontró más que manos que le empujaban a seguir bajando peldaños hacia el abismo.

\section{RANOCCHIO -RENACUAJO- Y LOS MINEROS: EL AUXILIAR Y LOS OPONENTES}

Es típico -o más bien obligado- que los héroes tengan un amigo o un auxiliar -a veces son varios, y forman incluso un equipo, como el de Arturo y los caballeros de la Tabla Redonda, o Carlomagno y sus Doce Pares-. Y que deban enfrentarse también 
a uno o a varios oponentes. Giovanni Verga, el demiurgo de Rosso Malpelo, bien lo sabía, y dejó trazos muy hábiles y originales -destilados en un minucioso proceso de inversión, claro- de todos ellos en su cuento.

Rosso Malpelo tiene, cuando es muy niño, alguien que le cuida y se preocupa por él: su padre. Pero la presencia de su padre en su vida termina abruptamente cuando una avalancha de piedra y arena sepulta al minero a escasos metros de donde, aturdido por el miedo, está el infeliz pelirrojo. Después, cuando crece, el amigo o auxiliar de Rosso Malpelo es otro desdichadísimo niño minero que, al igual que el protagonista, en vez de nombre lleva solo un apodo despectivo: el de Ranocchio, Renacuajo. Y que de auxiliar tampoco tiene mucho, porque era un niño más débil aún que Rosso.

Los enemigos u oponentes de Rosso Malpelo son todos los demás: la madre, la hermana, el resto de los mineros que no desaprovechan ninguna oportunidad para agredir física y moralmente al niño, y el dueño de la mina, que solo asoma en el cuento -muy de paso- cuando es importunado con el aviso de que el padre se ha muerto aplastado en la cantera.

Fijémonos primero en Renacuajo, un personaje con el que el protagonista establece una relación tan ambigua como contradictoria: protectora y generosa por un lado, prepotente y sádica por el otro. Análoga en lo primero, opuesta en lo demás, a los lazos de confianza total, de alianza sin condiciones, de reparto generoso de dones y de esfuerzos, que tiene que funcionar entre el héroe y su amigo o auxiliar:

Por una sutileza de su maldad había tomado bajo su protección a un pobre chico, que llevaba muy poco tiempo trabajando en la cantera, el cual, a causa de una caída desde lo alto de un puente, se había dislocado el fémur y no podía trabajar ya de peón. El desgraciado, cuando cargaba la espuerta de arena a la espalda, caminaba como si bailara una tarantela y era el hazmerreír del lugar, de modo que le pusieron el apodo de Renacuajo, aunque trabajando debajo de tierra, tan renacuajo como era, su pan bien que se lo ganaba, y Malpelo le daba además del suyo. Para darse el gusto de someterlo, decían (56).

Cada vez que a Renacuajo le tocaba un trabajo demasiado duro, y lloriqueaba como si fuera una muchachita, Malpelo le arreaba en el costado y le gritaba:

\footnotetext{
-Cállate, pollito -y si no callaba, se decidía a echarle una mano diciendo con un cierto orgullo-: Déjame a mí; yo soy más fuerte que tú.

O bien le daba su media cebolla y se contentaba con su mendrugo de pan seco, y se encogía de hombros, añadiendo:

- Yo estoy acostumbrado (57).
}

Se echaba a Renacuajo a la espalda y lo animaba a su manera, chillándole, pegándole. Cierta vez, al golpearlo por detrás, al chico le sobrevino una bocanada de sangre y Malpelo, asustado, estuvo buscándole alguna herida dentro de la nariz y de la boca, y juraba que no podía haberle hecho tanto daño con un golpe así, y para demostrárselo se daba fuertes porrazos en el pecho y en la espalda con una piedra; más aún, un obrero, allí presente, le arreó una patada en los riñones, una patada que resonó como si hubieran golpeado un tambor, y Malpelo ni siquiera se movió y, sólo cuando el obrero 
se fue, añadió: “-¿Lo ves? ¡No me ha hecho nada! Y su golpe ha sido más fuerte que el mío, jte lo juro (64)!"

Cuando el desdichado Renacuajo comienza a dar síntomas de la enfermedad que le llevará a la muerte, Rosso Malpelo le confirma, como siempre de un modo muy sui generis, las señales de su amistad, y también de su prepotencia:

Entonces Malpelo robó dinero de la paga de la semana para comprarle vino y menestra caliente y le dio sus pantalones casi nuevos porque lo cubrían mejor. Pero Renacuajo continuaba tosiendo y algunas veces parecía ahogarse. Y por la noche no había modo de apagar los escalofríos de la fiebre, ni con sacos, ni cubriéndolo con paja, ni arrimándolo a la lumbre. Malpelo permanecía en silencio e inmóvil inclinado sobre él, con las manos en las rodillas, mirándolo con esos ojos suyos abiertos de par en par como si quisiera hacerle un retrato, y cuando lo escuchaba gemir despacio, y veía su rostro jadeante y los ojos apagados, iguales a los del asno gris cuando resoplaba exhausto debajo de la carga mientras subía la trocha, le decía mascullando:

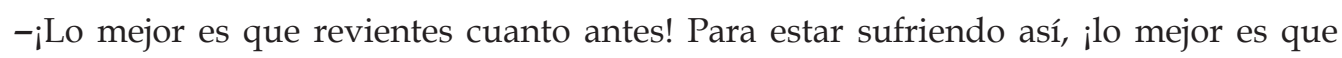
revientes!

El patrón comentó que no le quitaran ojo a Malpelo; era capaz de aplastarle la cabeza al muchacho (64-65).

Rosso Malpelo, aun siendo un personaje herido, acomplejado, que no es capaz de proyectar ni de canalizar bien su dolor y frustración, y que impone por ello una relación medio de alianza y medio de sometimiento a Renacuajo, es también el único ser del universo de la mina que siente lástima y piedad -si descontamos a su padre, y a la madre de Renacuajo, que llora desconsolada la muerte de su hijo- por su prójimo.

No solo eso: Malpelo es el único minero que se esfuerza por recuperar el cadáver de su padre, que quedó, sin que a nadie le preocupe lo más mínimo, bajo una montaña de piedras y de arena; que acude en ocasiones a recogerse (a veces con Renacuajo) al despeñadero en el que se pudre un asno hacia el que había mantenido una actitud de cariño y de crueldad análoga a la que proyectaba hacia su único amigo humano; y que, para evocar al Renacuajo que acaba de expirar, vuelve a acudir a la cita con los muertos en aquel mismo simbólico lugar, que él convierte en una especie de mísero altar de duelo y de memoria. Rosso Malpelo, el niño arisco y salvaje despreciado por todos, al que algunos -sugestionados por el rojo de su pelo- tenían incluso por compinche del demonio, es pues, como lo fueran en otros tiempos y lugares Príamo o Antígona, el único que muestra alguna preocupación por el descanso y por el recuerdo de los muertos. Otro quiebro genial de Giovanni Verga, capaz de pintar a su personaje con una paleta variadísima de colores, que van desde la violencia ocasional hacia el asno o el amigo desvalido -violencia que Rosso justifica porque “ ¡Lo mejor es que revientes cuanto antes! Para estar sufriendo así, ¡lo mejor es que revientes!"(64-65)- hasta el oficio del compromiso y la solidaridad con ellos aun después de muertos.

La relación de Rosso Malpelo con sus oponentes es igualmente muy original. Verga se esfuerza en insertarla de nuevo dentro de una tradición narrativa consuetudinaria, y en echarla a volar al mismo tiempo hacia horizontes y soluciones de lo más singular. 
Los oponentes de Rosso son casi todos: su madre, su hermana y el resto de los mineros -salvo Renacuajo-, y responden otra vez a una variedad de funciones y de registros asombrosa, pues sus armas de agresión van desde la indiferencia -la de la madre, por ejemplo- hasta la violencia justificada por la superstición que condenaba a Malpelo como gafe que atraía la desgracia a sus compañeros de la mina:

Si sucedía alguna desgracia, que un trabajador perdiera sus herramientas, o un burro se rompiera una pata, o se derrumbara un tramo de galería, siempre le echaban la culpa a él; y él aguantaba las palizas sin protestar, tal como las aguantan los asnos, que curvan el espinazo y continúan haciendo a su manera. Con los demás mozos era cruel. Parecía querer pagar en los más débiles el mal que imaginaba sufrieron su padre y él. En realidad, sentía una extraña satisfacción al recordar los maltratos e injusticias hechas a su padre y el modo en que lo dejaron morir (55).

\section{EL LINAJE -EL PASADO-, EL DESTINO -EL FUTURO-... Y EL HILO DEL RELATO}

Rosso Malpelo estaba trabajando al lado de su padre cuando una avalancha de arena sepultó al adulto y respetó, por muy poco, la vida del niño. El mal hado se conformó, aquella vez, con pasar rozándole:

Murió un sábado que quiso terminar cierto destajo, por culpa de una pilastra que una vez había servido de contrafuerte en las excavaciones, pero ya no servía para nada [...]. La gruesa pilastra roja, abierta en canal a golpes de azada, se contraía y doblaba como si tuviera dolor de estómago y también ella dijera: ¡ay! ¡ay! Malpelo estaba desescombrando el terreno y poniendo a buen resguardo el pico, el saco vacío y la garrafa de vino. El padre, encariñado de él, pobrecillo, le repetía: “iÉchate atrás!”: O bien: “iTen cuidado! Vigila si caen piedras o arena gruesa". De repente no dijo una palabra más, y Malpelo, que estaba de espaldas metiendo las herramientas en el cesto, oyó un ruido sordo y ahogado, como hace la arena cuando cae toda de un golpe, y la luz se apagó (53).

Nadie fue capaz de rescatar aquella noche los restos -lo poco que quedó del padre iría apareciendo meses después- sepultados por la avalancha. Y solo el entonces muy niño Rosso Malpelo fue capaz de mantener, en aquel cuadro de tragedia, la dignidad semibestial que le caracterizaba:

Con el gentío y el griterío no prestaron atención a una voz de muchacho, exenta de todo rasgo humano, que gritaba:

-¡Cavad! ¡Cavad aquí! ¡Rápido!

- Eh! -dijo el Cojo- ¡Es Malpelo!

- ¿Y de dónde ha salido Malpelo?

-De no haber sido Malpelo, no habría escapado, no.

Los otros se echaron a reír, y hubo quien sostuvo que el chico tenía al diablo de su parte, y quien dijo que tenía el pellejo duro como los gatos. Malpelo no respondía, ni siquiera lloraba, excavaba con las uñas en la arena, dentro del agujero, y nadie se percató de su presencia. Cuando se acercaron con una luz lo vieron con el rostro tan fuera de sí, y los ojos tan vidriosos, y tanta espuma en la boca, que daba miedo. Tenía las uñas rotas y le colgaban de las manos ensangrentadas (53).

El cordón umbilical que unía a Rosso Malpelo a la mina era, curiosamente, paterno, 
no materno. No es de extrañar: el minero era el padre -el único que lo sentía de su sangre y que mostraba solidaridad hacia él-, no la madre -una extraña para el hijo y para la mina, de los que huyó al quedarse viuda para casarse con otro hombre-. Y el aplastamiento de su padre -de su linaje, de su sangre, de su pasado- bajo el peso del mineral, cuando estaba al lado suyo, valía como anticipación de lo que sería su propia muerte, equivalía a aquellas contundentes declaraciones oraculares que presagiaban, en la antigua Grecia, el final que aguardaba al héroe marcado por la tragedia dinástica. Porque, como héroe trágico, o como infrahéroe que era, la derrota en toda regla de Rosso Malpelo estaba anunciada desde siempre. Su sangre venía de los muertos en lo oscuro de la mina, y su destino tenía que ser fatalmente ese también.

El agobiante determinismo que crea la atmósfera de opresión que destila todo el relato se ve reforzado por las lechuzas -aves con viejísimo simbolismo agorero y fúnebre- que aleteaban por los aledaños de la mina como parte del dispositivo oracular sutilmente levantado por el autor:

Para quienes estamos hechos a vivir bajo tierra, pensaba Malpelo, debería estar oscuro siempre, en todas partes. La lechuza ululaba en los alrededores, vagaba de un lado a otro, y él pensaba: La lechuza escucha a los muertos que yacen bajo tierra y se desespera porque no puede ir en su busca.

Renacuajo tenía miedo de las lechuzas y de los murciélagos, pero el pelirrojo le chillaba porque quien está obligado a vivir solo no puede permitirse tener miedo de nada [...].

Poco después, en la cantera dijeron que Renacuajo había muerto, y Malpelo pensó que ahora la lechuza también chillaría por él durante la noche, y volvió a visitar los restos descarnados del [burro] Gris, en el barranco, donde solía ir en compañía de Renacuajo (53).

Pero no eran solo los aleteos y los gritos de la lechuza los que diseminaban fúnebres agüeros y complicidades entre los vivos y los muertos de la mina. Otro lenguaje más expresivo y también más dolorido, el del propio Rosso Malpelo, era capaz de relatar a los vivos, hasta con cierto despliegue teatral, cómo eran las andanzas por la mina de los muertos:

Renacuajo tenía miedo; él, no. Él contaba que vivía allí desde siempre, desde niño, y siempre había tenido delante ese agujero negro que se perdía en la tierra, adonde el padre solía acompañarlo cogiéndolo de la mano. Entonces, abría los brazos a izquierda y derecha y describía cómo se extendía el intrincado laberinto de las galerías bajo sus pies, en todas las direcciones, por aquí, por allí, hasta donde se veía la colada volcánica renegrida y desolada, sucia de retamas requemadas, o contaba las historias de cuantos habían perdido su vida allí, o aplastados, o perdidos en la oscuridad en donde vagan desde hace años, y siguen vagando, sin encontrar la luz del pozo por el que descendieron, sin escuchar los gritos desesperados de los hijos a quienes buscan inútilmente.

Y Malpelo seguía contando que debajo de ellos había infinidad de galerías subterráneas, por todas partes, en dirección a la montaña y en dirección al valle. En cierta ocasión, un minero que entró con el pelo negro, volvió a salir con el pelo ya blanco; y otro al que se le apagó la antorcha estuvo pidiendo auxilio en vano, pues nadie podía escucharlo. ¡Sólo él habría oído sus propios gritos!, decía, y la sola idea, aunque tuviera el corazón duro como la lava, le hacía estremecerse.

-El patrón me manda dentro a menudo, a donde los demás tienen miedo de ir. Pero como yo soy Malpelo, nadie entrará a buscarme si no regreso (59-60, 62-63). 
Rosso Malpelo, el infrahéroe que se parecía a los (super)héroes en el reverso de casi todo, tenía el don de la narración y también el de la profecía, pues los relatos de fantasmas errantes que él disfrutaba contando a Renacuajo anticipaban el destino de fantasma errante que a él mismo le aguardaba en las entrañas de su mina. Quedémonos, al final de este triste cuento, con el consuelo de saber que para un buen narrador no hay muchos placeres comparables al de la ceremonia de narrar, y que Rosso Malpelo pudo disfrutar alguna vez, en su triste y escueta vida, de tal gozoso placer.

Mientras Hamlet agonizaba dejó encargado a su amigo Horatio que contase lo que había sido su vida y su muerte; Rosso Malpelo no pudo dejar ese encargo a nadie, porque en el momento en que murió -cargado con "las herramientas de su padre", porque la sangre del minero muerto llama a la sangre de su hijo- no tenía ya ningún amigo. Pero estaría encantado, como buen narrador que era, de saber que su historia y sus historias de fantasmas siguen siendo relatadas en el presente. Y que, por más que moleste, "y mucho, al patrón", "la cantera de Malpelo" sigue siendo hoy muy bien conocida:

Cuando le encomendaron aquella inspección se acordó del minero extraviado que, desde hace años y años, vaga y vaga por la oscuridad pidiendo auxilio, sin que nadie pueda oírlo.

No dijo nada. En fin, ¿de qué habría servido? Cogió las herramientas de su padre, el pico, la azada, la linterna, el saco de pan y la garrafa de vino, y se fue; nunca más se supo de él.

Se perdieron incluso los huesos de Malpelo. En las galerías, los muchachos en la cantera bajan la voz cuando hablan de él; tienen miedo de verlo aparecer de repente, el cabello pelirrojo, los ojos grises (67).

El final de la vida de Rosso Malpelo no podía dejar de ajustarse, por supuesto, a viejos patrones mitológicos. El encargo de realizar cierta hazaña arriesgada en algún lugar lleno de peligros, con el propósito -más o menos manifiesto- de eliminar al viajero, se halla engastado en un sinnúmero de mitos, epopeyas, cuentos. Recuérdese, sin ir más lejos, a Jasón, enviado por su perverso tío Pelias a los confines de la Cólquide, embarcado en la búsqueda -que se preveía suicida- de un vellocino de oro inviolable hasta entonces. $\mathrm{O}$ al héroe esclavo por excelencia, Heracles, comisionado por su primo, el celoso y cobarde Euristeo, para que realizase doce trabajos imposibles en los extremos -algunos de ellos infernales- más amenazantes del mundo.

Rosso Malpelo, el infrahéroe, no podía quedar sin recibir también el encargo de hacer una incursión -disfrazada en el relato de Verga de prosaica "inspección" - en el vientre mismo del infierno. Pero, a diferencia de Jasón, o de Hércules, o de tantos otros viajeros épicos, el niño pelirrojo nunca regresó. Por no saberse, no se sabe ni quién le había encomendado aquel fatídico y postrer trabajo. ¿Qué importaba? Sería alguno de sus jefes de la mina, o algún minero más avisado que temía asumir personalmente 
aquella "inspección", o sería la indiferencia de todos... O puede que fueran -eso con un alto grado de probabilidad- las reglas del relato heroico, que habían de ser llamadas e invertidas, en el trance de su muerte, del mismo modo en que lo fueron mientras duró su vida.

\section{BibLIOGRAFÍA}

Gracia, P. (1991): Las señales del destino heroico, Barcelona, Montesinos.

Gutiérrez Carbajo, F. (1993): “La leyenda de Judas y sus variantes", en José Romera, Antonio Lorente y Ana $\mathrm{M}^{\mathrm{a}}$ Freire, eds., Ex libris. Homenaje al Profesor José Fradejas Lebrero, Madrid, UNED, vol. II, 805-819.

La infancia de Baybars [Romance de Baybars, 1] (2003): traducido del árabe al francés y anotado en este idioma por Georges Bohas y Jean-Patrick Guillaume, traducido del francés al español y anotado por $\mathrm{M}^{\mathrm{a}}$ Jesús Díaz Orueta, Madrid, Ediciones Jaguar.

Pedrosa, J. M (en prensa): “Superos / Medio / Inferos: los héroes suspendidos entre el cielo y la tierra".

Piñero Ramírez, P. M. (ed.) (1995): Descensus ad inferos: La aventura de ultratumba de los héroes (de Homero a Goethe), Sevilla, Universidad.

Verga, G. (2009): "Malpelo el pelirrojo", Cavallería rusticana y otros cuentos sicilianos, traducción, prólogo y notas de José Abad, Granada, Traspiés, 51-67. 